\title{
Systematic Research on Predictive Models on Students' Academic Performance in Higher Education
}

\author{
Faiz Zulkifli, Zulkifley Mohamed, Nor Afzalina Azmee
}

\begin{abstract}
In Malaysia, the students' academic assessment has changed over time as it is now made to be more holistic. Predictive models used for educational data in Malaysia are still inadequate in giving a true picture of the students' academic performance. The reason behind this is due to the lack of research in Malaysian context on predictive models and factors affecting students' academic achievement. Therefore, this study will conduct a systematic review on the literature, in order to identify the predictive methods for students' academic performance in higher education. Through three major bases: WoS, Science Direct and IEEE Xplore, an extensive search was conducted to find any related articles from 2014 to 2018 that use "predict", "forecast", "academic performance", "student" and "higher education" keywords in their text. Initially, 195 articles were selected to be used in this review. However, through titles and abstracts' filtering and screen processing, only 69 articles found to discuss on the predictive model for student's academic performance at higher education level. Based on extensive reading, the most widely used attributes in the predictive models is the academic process. While predictive models can be categorized into three, namely classification, cluster and regression, there are nine methods used by previous researchers in all categories. The most widely used category from previous studies was the classification, with 33 articles. This study has listed the advantages and disadvantages of each method based on the previous studies. This study also has identified the challenges and gaps faced by previous researchers in improving the existing models in the future. Among the challenges faced by the predictive models are the amount of data and assumptions that need to be followed before analysis can be made. In the future, the predictive models used for students' academic performance should consider the latest assessments' valuation method based on a modern educational system that emphasizes on soft skills, interpersonal skills and high-level thinking capabilities.
\end{abstract}

Index Terms: Classification, clustering, higher education, regression, students' academic performance.

\section{INTRODUCTION}

Students' academic performance has become an important issue for all levels of education especially in higher education levels. Students' performance has become one of the key performance indices in determining the rank of an institution as opposed to other institutions that are academic performance has become one of the most popular

Revised Manuscript Received on July 10, 2019.

Faiz Zulkifli, Faculty of Computer and Mathematical Sciences, Universiti Teknologi MARA Perak Branch, Tapah Campus, 35400 Tapah Road, Perak, Malaysia.

Zulkifley Mohamed, Department of Mathematics, Faculty of Science and Mathematics, Universiti Pendidikan Sultan Idris, 35900 Tanjong Malim, Perak, Malaysia.

Nor Afzalina Azmee, Department of Mathematics, Faculty of Science and Mathematics, Universiti Pendidikan Sultan Idris, 35900 Tanjong Malim, Perak, Malaysia. equivalent to it. Hence, the predictive model of students'

research topics lately. Producing a good predictive model can benefit both students and institutions. Institutions can improve the academic quality of students and optimize the resources available to help students in completing their programs at in allocated time. Additionally, research findings identify potential students and provide advice to them by recommending remedial actions, so that they can better improve their academic performance in the future.

Currently, there are many methods proposed by researchers in various fields in evaluating their students' academic performance. The built model is based on statistical and mathematical models that can accurately measure the accuracy of the model. Use of algorithms or computer routines can help calculate formulas easily and quickly. The use of technology can also help store data and information in large capacity, thereby producing better prediction results as it considers the large number of samples approaching the population. Although the production of models can be accurate to an extent, it can still be improved according to the latest education system circulation which has different assessment methods than usual. In Malaysia, the assessment methodology of the students' assessment has changed according to the needs of today's industry which requires an integrated assessment mechanism. This mechanism could provide reports on students' achievement and development that deliberates the rise in manners, knowledge, capabilities and high-level thinking skills

This study will review the current literature on the predictive model of students' academic performance at higher education level. In continuing the systematic review process, the types of methods and factors used in the previous studies were structured for reference purposes, in order to achieve the objectives of the study. There are three main objectives in this study. First, it is to identify the factors or attributes that are considered in the previous studies of the predictive model of students' academic performance. Next, it is to identify the predictive model of students' academic performance and identify the advantages and disadvantages of those methods. Lastly, to examine the challenges and gaps in every model ever used based on suggestions from previous researchers as well as current issues in the education system especially in Malaysia. 


\section{SYSTEMATIC RESEARCH ON PREDICTIVE MODELS ON STUDENTS' ACADEMIC PERFORMANCE IN HIGHER EDUCATION}

\section{METHODOLOGY}

The most important keyword covered in this study is "prediction models". The factors that contributed to students' performance are academic process, demographic and students' personality. All these factors were further explained in the next section. This study also solely looked at predictive models for students in higher education.

\section{A) Article Sources}

A comprehensive review of all articles related to prediction models is made through the best and most reliable databases such as the Science Direct database, IEEE Xplore library and Web of Science (WoS) service. All these databases provide access to articles related to science, technical, social sciences, arts and humanities.

\section{B) Article Selection Procedures}

Procedures for selecting relevant studies started with the search for appropriate past articles. The procedures consisted of two stages, namely scanning and filtration. The first stage was isolation for irrelevant and duplicated articles through scanning of titles and abstracts. The second stage was isolation of the article after reading the complete text of the first screened articles. Both levels used the same appropriate criteria in selecting predictive models for exam performance related articles.

\section{C) Search}

Extensive search on past studies dated from 2014 to 2018 has been made through WoS, Science Direct and IEEE Xplore search engines. Various keywords were put into their search box by using combination of "predict", "forecast", "academic performance", "student", and "higher education" keywords. The combinations of keywords varies with the use of the OR and AND operator. Fig. 1 shows the number of articles that have been screened and selected for this study.

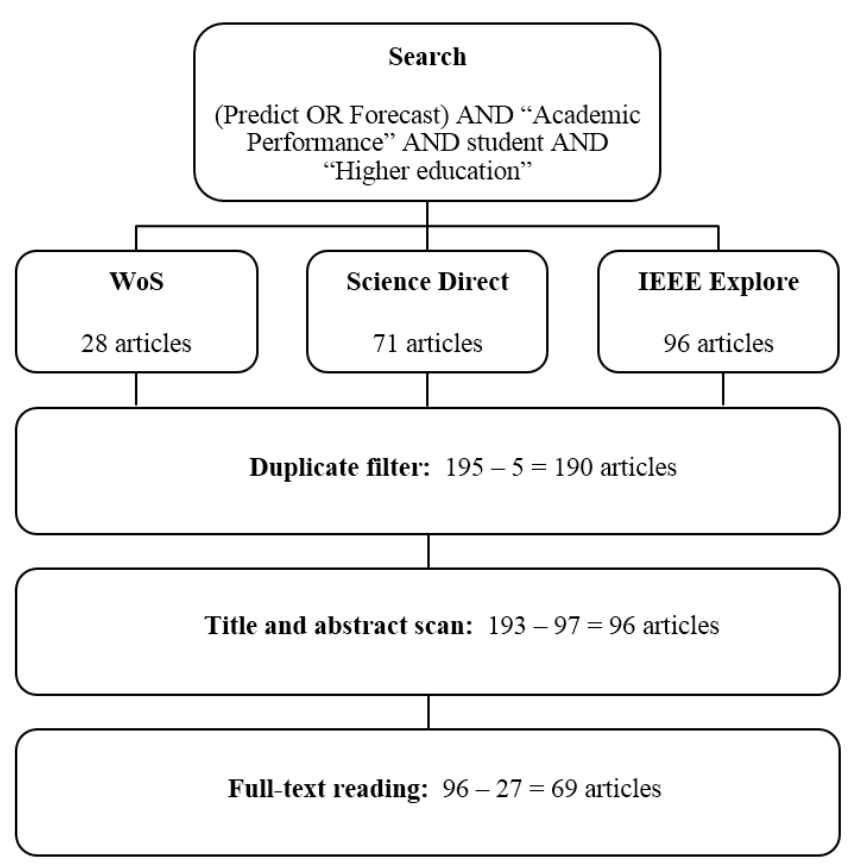

Fig. 1: Flowchart of sources selection

\section{D) Consideration and Rejection Criteria}

Specific criteria needed to be prepared, in order for the search of articles was focused within the scope of the desired topics. As mentioned earlier, this study examines predictive models for academic performance of students Therefore, the main criteria considered for article selection is on the method of study, where it should measure students' performance using mathematical or statistical methods. The data that has been used in literary studies consisted of simulated data or actual data. However, the target respondents are among the students in higher education. This study only looked at past studies that examined students' performance at higher education levels. Generally, learning in higher institution would be the last pit stop before entering any employment scenes for the students. It is therefore important for universities to produce quality graduates in accordance with market expectations. At this stage, it is also assumed that students possess high maturity level in thinking and being able to control emotion well throughout the learning and teaching process. A good predictive model of students' academic performance should be able to identify problematic students. Thus, it helps them in refining performance through the improvement process in the education system. In addition, the general criterion for the articles is to use English language as the medium in the text. The resource for this study was focused on journals and conference articles that reflect recent research and have been adopted by other researchers as source of reference. General reports, books or chapters in a book were excluded in this study. The previous articles in the form of systematic review would not be considered as a source for this study. This is because the recruitment of referrals from non-original sources will result in information being obtained inaccurate and biased to some of the methods involved.

\section{E) Resource Collection Procedure}

All articles obtained from numerous sources were stored in one file to facilitate the next process. To encourage filtering and screen processing, the use of the Mendeley software was required. This software was comprehensive and helped researchers in the process of compiling, reading and quoting the resources in a single storage space. The downloaded articles were exported into the software library. Next, any duplicate articles were identified and removed from the storage. The selected articles were summarized into a table detailing information relating to the title, author name, publication year, data type, variables, method, discovery and future work. All information was saved in Word file. Summary of information is important in identifying similarities or differences between previous studies. The gap in previous studies should be noted for future research purposes. The gap may exist in methods, types of variables and the used data. Many researchers agreed that there is no perfect method to predict students' performance in different time and circumstances. However, the best method can be determined by measuring the difference in estimated value and actual value using the appropriate valuation process. Through the reading of the variables used by the researchers, it differs based on their assumptions declared during the preliminary 
stage of the study. The amount of data that have been used also varied due to limited source. The results of the analysis on the wide searching and reading are discussed in detail in the next section.

\section{EXTENSIVE SEARCH RESULT}

At the beginning of the search, a total of 195 articles dated from 2014 to 2018 were linked to the focus of the study (28 articles from WoS, 71 articles from Science Direct and 96 articles from IEEE Explore). There are five articles that have been duplicated on all three sources and were removed from the article list, only one article from the duplicate was left behind. Through article titles and abstracts, only 96 articles were found to really discuss on predictive methods for students' academic performance. Meanwhile, only 69 articles used predictive methods for higher education and they are not reviewed articles from past studies. All the 69 articles were read extensively to identify gaps for improvement purposes. Out of the 69 articles, $33(47.83 \%)$ articles used classification method in predicting the academic performance of students for higher education. Whereas, there were $3(4.35 \%)$ articles and 19 (27.54\%) articles used clustering and regression methods, respectively. Additionally, $11(15.93 \%)$ articles used both classification and regression methods in their study. Only 3 $(4.35 \%)$ articles used both clustering and regression methods. The definitions and differences in classification, clustering and regression methods are described in detail in the next section.

\section{IMPERATIVE ATTRIBUTES CONSIDERED IN PREDICTING MODEL}

This section discusses on the key attributes that affect students' academic performance. Based on extensive reading, these attributes can be categorized into three main categories; academic process, demographic and students' personality. The most frequently used attribute in the previous study was the academic process where 27 (39.13\%) articles had used this attribute in their study. The academic process consists of the attendance, student learning time, learning activities, notes, teaching methods, tests, quizzes, lab work, assignments and previous academic performance. The attributes categorized as demographics are gender, age, race, language of conversation, origin, guardian job, guardian educational background and socio-economic. Meanwhile, the attributes for students' personality consist of learning methods, motivation, learning attitudes, emotional or pressure control skills, decision-making skills, and addiction to technology or social media. There are 24 $(34.78 \%)$ articles that have attributed the academic and demographic processes as their study variables. Next, 15 $(21.74 \%)$ articles have incorporated the academic and students' personality processes as research attributes. The rest, $3(4.35 \%)$ articles have used all three categories of attributes as variables in the predictive model on students' academic performance. However, there is no study that used only one category of attributes for the demographic or student personality in determining the student's academic performance. This is likely because they ought to evaluate the extent to which the developed model is able to predict the academic performance of the students accurately on the final evaluation or average percent grade for the assessed semester. Normally, final assessments are evaluated in a more objectively written examination.

\section{PREDICTIVE MODELS USED IN PREVIOUS STUDIES \& RESULTS}

There are various methods that have been developed and used in previous studies to predict students' academic performance. It can be grouped into three types, namely classification, clustering and regression. Each group has various methods that were developed according to their respective goals. So, the definition of the methods and identification of the advantages and disadvantages will be done in this section.

In general, classification is a method used in identifying the categories of groups from new observations in known categories' existing group sets. For example, observation is categorized by gender or origin. Based on the reading, there are five classification methods used in the previous study, which are Bayes Classification (BC), K-Nearest Neighbor (KNN), Logistic Regression (LR), Support Vector Machine (SVM) and Classification Trees (CT).

Whereas, clustering is the process of dividing data or populations into groups that have almost identical characters or patterns but differ between groups. From previous studies, among the methods used for clustering are Principal Component Analysis (PCA), K-Means Clustering (K-M C), and Hierarchical Clustering (HC).

The definitions of each method, advantages and disadvantages for each classification, clustering and regression methods are given in the following Table 1.

Table 1: Definition, advantages, disadvantages and references for each methodB

\begin{tabular}{|c|l|l|l|l|}
\hline Methods & \multicolumn{1}{|c|}{ Definition } & \multicolumn{1}{|c|}{ Advantage } & Disadvantage \\
\hline BC & $\begin{array}{l}\text { The Bayesian classification } \\
\text { (BC) is derived from the } \\
\text { Bayesian Theorem. Bayesian } \\
\text { classification is a statistical } \\
\text { method that can determine } \\
\text { the class of an observation } \\
\text { based on the probability } \\
\text { value. }\end{array}$ & $\begin{array}{l}\text { Well-fitting over small } \\
\text { data sets due to low } \\
\text { variance values. }\end{array}$ & $\begin{array}{l}\text { Not suitable for correlated data and } \\
\text { independence assumptions are not } \\
\text { followed. It always applies to large } \\
\text { data. }\end{array}$ \\
\hline
\end{tabular}




\section{SYSTEMATIC RESEARCH ON PREDICTIVE MODELS ON STUDENTS' ACADEMIC PERFORMANCE IN HIGHER EDUCATION}

\begin{tabular}{|c|c|c|c|c|}
\hline KNN & $\begin{array}{l}\text { K-Nearest Neighbor (KNN) } \\
\text { is a method that uses simple } \\
\text { algorithms to store all } \\
\text { available class information } \\
\text { and further classify new } \\
\text { observation data based on } \\
\text { similarity measurements. } \\
\text { KNN is a non-parametric } \\
\text { technique that has been used } \\
\text { in recognizing patterns and } \\
\text { statistical estimates. }\end{array}$ & $\begin{array}{l}\text { The KNN properties that } \\
\text { use a little code make it } \\
\text { very easy to understand } \\
\text { and implement. } \\
\text { Assumptions about the } \\
\text { probability of a data are } \\
\text { not needed in generating } \\
\text { algorithms. }\end{array}$ & $\begin{array}{l}\text { KNN's computation is made during } \\
\text { the test rather than during the training. } \\
\text { It will be difficult at the time of } \\
\text { calculation if it involves considerable } \\
\text { data. } \\
\text { This method obtains all the } \\
\text { information from local inputs and } \\
\text { anomalies. So, it is very sensitive to } \\
\text { changes to local data. }\end{array}$ & {$[1]-[6]$} \\
\hline$\overline{\mathrm{LR}}$ & $\begin{array}{l}\text { Logistic regression (LR) is a } \\
\text { method for estimating } \\
\text { parameters for logistics } \\
\text { model. The logistics model } \\
\text { sees linear combinations } \\
\text { between dependent and } \\
\text { independent variables in log- } \\
\text { odds probability values. All } \\
\text { the variables used only have } \\
\text { two response options. }\end{array}$ & $\begin{array}{l}\text { This method uses a } \\
\text { probabilistic approach } \\
\text { which satisfies statistical } \\
\text { characteristics that } \\
\text { emphasize the } \\
\text { probability of an event. } \\
\text { It allows other statistical } \\
\text { inference methods to be } \\
\text { applied in this model. }\end{array}$ & $\begin{array}{l}\text { To use this method all the } \\
\text { assumptions on the linear regression } \\
\text { model should be followed. Among } \\
\text { the difficult assumptions to follow is } \\
\text { the dependency of variables between } \\
\text { one another. Disregarding } \\
\text { assumptions caused the model to be } \\
\text { less accurate. }\end{array}$ & {$[4]-[8]$} \\
\hline SVM & $\begin{array}{l}\text { Support Vector Machine } \\
\text { (SVM) is a classifier that } \\
\text { adopts the hyperplane } \\
\text { separation method. By using } \\
\text { labeled data, optimum } \\
\text { hyperplane can be generated } \\
\text { from algorithms that classify } \\
\text { new categories. }\end{array}$ & $\begin{array}{l}\text { This method gives a high } \\
\text { accuracy because it uses } \\
\text { a good theoretical } \\
\text { background to the } \\
\text { estimation and it is } \\
\text { appropriate for non- } \\
\text { linear data }\end{array}$ & $\begin{array}{l}\text { The result of this method is quite } \\
\text { difficult to explain and takes a lot of } \\
\text { time to estimate the new category as } \\
\text { the support vector is too large. }\end{array}$ & $\begin{array}{c}{[5],[6],} \\
{[9]}\end{array}$ \\
\hline CT & $\begin{array}{l}\text { The classification tree }(\mathrm{CT}) \\
\text { can predict the classification } \\
\text { of dependent variables by } \\
\text { making measurements } \\
\text { against dependent variables. }\end{array}$ & $\begin{array}{l}\text { This method works well } \\
\text { without the need for } \\
\text { scaling and can be } \\
\text { applied to linear and } \\
\text { non-linear data. }\end{array}$ & $\begin{array}{l}\text { Excessive fit may occur with little } \\
\text { data and makes poor decision. }\end{array}$ & $\begin{array}{c}{[1]-[3],} \\
{[6],[10]-} \\
{[13]}\end{array}$ \\
\hline PCA & $\begin{array}{l}\text { Principal component analysis } \\
\text { (PCA) is a method that } \\
\text { converts the original variable } \\
\text { into a small set of linear } \\
\text { combinations by considering } \\
\text { the amount of variance in the } \\
\text { data. It is also known as } \\
\text { factor analysis. }\end{array}$ & $\begin{array}{l}\text { This method does not } \\
\text { require fixed } \\
\text { assumptions for which } \\
\text { data can be used on all } \\
\text { types of data. It is also } \\
\text { suitable for use with } \\
\text { large data. }\end{array}$ & $\begin{array}{l}\text { This method is difficult to use against } \\
\text { data that has a non-linear } \\
\text { combination. }\end{array}$ & [14] \\
\hline K-M C & $\begin{array}{l}\text { K-means clustering (K-M C) } \\
\text { is an approach that separates } \\
\text { data regularly according to } \\
\text { the K-clause and becomes a } \\
\text { cluster that does not overlap. } \\
\text { It is arguably the easiest } \\
\text { method to divide data. }\end{array}$ & $\begin{array}{l}\text { This simple method } \\
\text { allows the results to be } \\
\text { described easily as } \\
\text { compared to other } \\
\text { methods. It is also said to } \\
\text { be flexible and more } \\
\text { efficient. }\end{array}$ & $\begin{array}{l}\text { Through this method the number of } \\
\text { clusters should be set before analysis } \\
\text { is done. This means that this method } \\
\text { does not allow the construction of } \\
\text { models with the most optimum } \\
\text { number of clusters based on data } \\
\text { patterns. }\end{array}$ & [15] \\
\hline $\mathrm{HC}$ & $\begin{array}{l}\text { Hierarchical clustering (HC) } \\
\text { is a method of building a } \\
\text { hierarchy of clusters } \\
\text { comprising two strategies of } \\
\text { agglomerative and divisive. }\end{array}$ & $\begin{array}{l}\text { This method does not } \\
\text { require the determination } \\
\text { of the cluster's number } \\
\text { before analysis and it is } \\
\text { easy to implement. }\end{array}$ & $\begin{array}{l}\text { This method does not allow the } \\
\text { currently used algorithm to be } \\
\text { corrected after analysis has been } \\
\text { made. Sometimes dendrograms } \\
\text { diagrams could not show clusters } \\
\text { clearly and correctly. }\end{array}$ & [14] \\
\hline
\end{tabular}




\begin{tabular}{|c|c|c|c|c|}
\hline RA & $\begin{array}{l}\text { Regression analysis (RA) is a } \\
\text { statistical process in } \\
\text { estimating the relationship } \\
\text { between dependent variables } \\
\text { and independent variables. } \\
\text { Through the regression } \\
\text { model that has been built, the } \\
\text { dependent variable can be } \\
\text { predicted easily using the } \\
\text { desired independent variable. }\end{array}$ & $\begin{array}{l}\text { This method is an } \\
\text { efficient method in } \\
\text { predictive models that } \\
\text { can use more than one } \\
\text { factor variable. The } \\
\text { result of the analysis is } \\
\text { also easy to explain. }\end{array}$ & $\begin{array}{l}\text { This method needs to meet some } \\
\text { assumptions of the regression model } \\
\text { before actual analysis can be carried } \\
\text { out. The estimators for this model are } \\
\text { very easily influenced by extreme } \\
\text { data. The production of complex } \\
\text { models makes it difficult to assess the } \\
\text { accuracy. }\end{array}$ & $\begin{array}{c}{[4],[14],} \\
{[16]-[29]}\end{array}$ \\
\hline
\end{tabular}

This section discusses on the challenges and gaps for models that have been used in predicting students' academic performance. Challenges and gaps may occur in the methods and attributes that have been used in previous studies. Gaps on forecasting models can also occur when there are changes in the education system employed by a country. The changes that directly affect the model are from a change in the nature of the assessment to the students' academic performance.

Through the systematic review that has been made in this study, it is found that the methods most often used by previous researchers can be categorized into three, namely classification, cluster and regression. However, there are recent methods that have incorporated different fields into their methods such as data mining as in [13], [30], [31]. machine learning, statistics, and database systems to identify patterns in large data sets. In data mining method, predictive models using classification method have been categorized as supervised learning. A supervised learning can be defined as learning to teach or train machines to recognize data through good labeling. Meanwhile, the prediction by using cluster is better known as unsupervised learning in data mining approach. Unsupervised learning takes place by training machines to recognize unlabeled data but allowing them to use algorithms against the data without guidance [32], [33].

Challenges faced by each method are generally stated in the advantages and disadvantages previous research. Predictive results using classification and cluster methods by previous researchers only predict students according to the predetermined class, not following the performance of the individuals involved [34], [35]. Many researchers could not distinguish between classification and cluster methods. The challenges encountered using regression methods are that data must be quantitative, normalized, no extreme data and no multicollinearity. Data with extreme values and attributes used in relation to one another leads to improper use of estimates [36], [37]. The amount of data sampling used in the data mining method must be large so that the generalization of the population can be created as in [38] [41]. In addition, there are problems in obtaining the required attributes in the study. Sometimes the data obtained can be incomplete.

\section{CONCLUSION}

The academic performance's predictive models of students can help teachers and students improve their learning and teaching process. This study examines the research done by previous researchers to find out the methods and attributes that were used in their respective studies. The most widely Data mining is a method that combines methods between

used methods of estimating students' academic performance are the classification method, followed by regression method. On the other hand, academic processes is always used by previous researchers which include attendance, student learning time, learning activities, notes, teaching methods, tests, quizzes, lab work, assignments and previous academic performance. Other than that, the challenges or gaps faced in the process of predicting students' performance takes on the methods and attributes used. In addition, current students' performance assessments involving interpersonal skills and high-level thinking skills [42] should also be applied in the predictive model. In line with the focus of today's researchers who are more focused on the study of deep learning methods, impending research on predictive model of students' academic performance should consider the changes that occur in the current education system that also prioritize the achievement of soft skills, interpersonal skills and high-level thinking skills.

\section{ACKNOWLEDGMENT}

Researchers would like to acknowledge UiTM for providing funding for Scopus publication. Researchers would also like to express gratitude towards UiTM for giving them the opportunity to conduct this study.

\section{REFERENCES}

1. S. Taruna, and M. Pandey, "An empirical analysis of classification techniques for predicting academic performance," IEEE Int. Adv. Comput. Conf., 2014, pp. 523-528.

2. A. Sharabiani, F. Karim, A. Sharabiani, M. Atanasov, and H. Darabi, "An enhanced Bayesian network model for prediction of students' academic performance in engineering programs," IEEE Glob. Eng. Educ. Conf., 2014, pp. 832-837.

3. M. Mayilvaganan, and D. Kalpanadevi, "Comparison of classification techniques for predicting the cognitive skill of students in education environment," IEEE Int. Conf. Comput. Intell. Comput. Res., 2014, pp. 1-4.

4. J. Xu, K. H. Moon, and M. van der Schaar, "A machine learning approach for tracking and predicting student performance in degree programs," IEEE J. Sel. Top. Signal Process., 11(5), 2017, pp. 742-753.

5. J. Gamulin, O. Gamulin, and D. Kermek, "Comparing classification models in the final exam performance prediction," IEEE 37th International Convention on Information and Communication Technology, Electronics and Microelectronics, 2014, pp. 663-668. 
6. F. Marbouti, H. A. Diefes-Dux, and K. Madhavan, "Models for early prediction of at-risk students in a course using standards-based grading," Comput. Educ., 103, 2016, pp. 1-15.

7. J. L. Arco-Tirado, F. Fernández-Martín, A. M. RamosGarcía, L. Littvay, and J. Villoria, "A counterfactual impact evaluation of a bilingual program on students' grade point average at a Spanish university," Eval Program Plann., 68, 2018, pp. 81-89.

8. A. Krasilnikov, and A. Smirnova, "Online social adaptation of first-year students and their academic performance," Comput. Educ., 113, 2017, pp. 327-338.

9. S. E. Sorour, T. Mine, K. Godaz, and S. Hirokawax, "Comments data mining for evaluating student's performance," IEEE 3rd Int. Conf. Adv. Appl. Informatics, 2014, pp. 25-30.

10. T. M. Christian, and M. Ayub, "Exploration of classification using NBTree for predicting students' performance," IEEE Int. Conf. Data Softw. Eng., 2014, pp. $1-6$.

11. S. M. M. Rubiano, and J. A. D. Garcia, "Formulation of a predictive model for academic performance based on students' academic and demographic data," IEEE Front. Educ. Conf., 2015, pp. 1-7.

12. S. C. Kumar, E. D. Chowdary, S Venkatramaphanikumar, and K. V. K. Kishore, "M5P model tree in predicting student performance: A case study," IEEE Int. Conf. Recent Trends Electron. Inf. Commun. Technol., 2016, pp. 1103-1107.

13. B. Minaei-Bidgoli, D. A. Kashy, G. Kortemeyer, and W. F. Punch, "Predicting student performance: An application of data mining methods with an educational web-based system," 33rd ASEE/IEEE Annu. Front. Educ., 2003, pp. 1-6.

14. A. Pardo, F. Han, and R. A. Ellis, "Combining university student self-regulated learning indicators and engagement with online learning events to predict academic performance," IEEE Trans. Learn. Technol., 10(1), 2017, pp. 82-92.

15. J. Jamesmanoharan, "Discovering students' academic performance based on GPA using K-Means clustering algorithm," IEEE World Congress on Computing and Communication Technologies, 2014, pp. 200-202.

16. Y. Olufadi, "A configurational approach to the investigation of the multiple paths to success of students through mobile phone use behaviors," Comput. Educ., 86, 2015, pp. 84-104.

17. T. Bonsaksen, T. Brown, H. B. Lim, and K. Fong, "Approaches to studying predict academic performance in undergraduate occupational therapy students: A crosscultural study," BMC Med. Educ., 17(1), 2017, pp. 1-9.

18. F. Williamson, E. Espinosa, M. Quintana, and R. Alarcon, "Do cognitive factors predict student's academic performance in dental school?" 10th International Technology, Education and Development Conference, pp. 1-7.

19. C. E. Bai, W. Chi, and X. Qian, "Do college entrance examination scores predict undergraduate GPAs? A tale of two universities," China Econ. Rev., 30, 2014, pp. 632-647.

20. T. Joyce, S. Crockett, D. A. Jaeger, O. Altindag, and S. D. O'Connell, "Does classroom time matter?" Econ. Educ. Rev., 46, 2015, pp. 64-77.

21. A. Slim, G. L. Heileman, J. Kozlick, and C. T. Abdallah, "Employing Markov networks on curriculum graphs to predict student performance," IEEE 13th Int. Conf. Mach. Learn. Appl., 2014, 2014, pp. 415-418.

22. Z. Li, C. Shang, and Q. Shen, "Fuzzy-clustering embedded regression for predicting student academic performance," IEEE Int. Conf. Fuzzy Syst., 2016, pp. 344-351.

23. D. Piffer, D. Ponzi, P. Sapienza, L. Zingales, and D. Maestripieri, "Morningness-eveningness and intelligence among high-achieving US students: Night owls have higher GMAT scores than early morning types in a topranked MBA program," Intelligence, 47, 2014, pp. 107112

24. P. M. Arsad, N. Buniyamin, and J. A. Manan, "Neural network and linear regression methods for prediction of students' academic achievement," IEEE Glob. Eng. Educ. Conf., 2014, pp. 916-921.

25. T. Kötter, J. Wagner, L. Brüheim, and E. Voltmer, "Perceived medical school stress of undergraduate medical students predicts academic performance: An observational study," BMC Med. Educ., 17(1), 2017, pp. $1-6$.

26. P. Vuttipittayamongkol, "Predicting factors of academic performance," IEEE 2nd Asian Conf. on Defence Technol., 2016, pp. 161-166.

27. F. K. Kheng, N. Azlan, S. N. D. Ahmad, N. L. H. Leong, and I. Mohamed, "Relationship between cognitive factors and performance in an introductory statistics course: A Malaysian case study introduction," Malaysian Journal of Mathematical Sciences, 10(3), 2016, pp. 269-282.

28. T. Thiele, D. Pope, A. Singleton, and D. Stanistreet, "Role of students' context in predicting academic performance at a medical school: A retrospective cohort study," BMJ Open, 6(3), 2016, pp. 1-11.

29. D. K. Wentworth and J. H. Middleton, "Technology use and academic performance," Comput. Educ., 78, 2014 pp. 306-311.

30. S. S. Athani, S. A. Kodli, M. N. Banavasi, and P. G. S. Hiremath, "Student performance predictor using multiclass support vector classification algorithm," IEEE International Conference on Signal Processing and Communication, 2017, pp. 170-174.

31. B. Guo, R. Zhang, G. Xu, C. Shi, and L. Yang, "Predicting students performance in educational data mining," IEEE Int. Symp. Educ. Technol., 2015, pp. $125-128$.

32. V. Ramesh, P. Parkavi, and K. Ramar, "Predicting student performance: A statistical and data mining approach," International Journal of Computer Applications, 63(8), 2013, pp. 35-39.

33. T. Mishra, D. Kumar, and S. Gupta, "Mining students" data for prediction performance," IEEE Int. Conf. Adv. Comput. Commun. Technol., 2014, pp. 255-262.

34. S. Rajeswari, and R. Lawrance, "Classification model to predict the learners' academic performance using big data," IEEE Int. Conf. Comput. Technol. Intell. Data Eng., 2016, pp. 1-6.

35. S. Rana, and R. Garg, "Application of hierarchical clustering algorithm to evaluate students performance of an institute," IEEE 2nd Int. Conf. Comput. Intell. Commun. Technol., 2016, pp. 692-697.

36. A. M. Kueider, J. M. Parisi, A. L. Gross, and G. W. Rebok, "Computerized cognitive training with older adults: A systematic review," Plos One, 7(7), 2012, pp. $1-13$.

37. K. Macauley, L. Plummer, C. Bemis, G. Brock, C. Larson, and J. Spangler, "Prevalence and predictors of anxiety in healthcare professions students," Heal. Prof. Educ., 4(3), 2018, pp. 176-185.

38. N. A. Yassein, R. G. M. Helali, and S. B. Mohomad, "Predicting student academic performance in KSA using data mining techniques," J. Inf. Technol. Softw. Eng., 7(5), 2017, pp. 187-191 
39. V. Mhetre, and M. Nagar, "Classification based data mining algorithms to predict slow, average and fast learners in educational system using WEKA," IEEE Int. Conf. Comput. Methodol. Commun., 2018, pp. 475-479.

40. A. M. Shahiri, and W. Husain, "A review on predicting student's performance using data mining techniques," Procedia Computer Science, 72, 2015, pp. 414-422.

41. P. Guleria, N. Thakur, and M. Sood, "Predicting student performance using decision tree classifiers and information gain," IEEE Int. Conf. Parallel, Distrib. Grid Comput., 2014, pp. 126-129.

42. F. Zulkifli, R. Z. Abidin, N. F. M. Razi, N. H. Mohammad, R. Ahmad and A. Z. Azmi, "Evaluating quality and reliability of final exam questions for probability and statistics course using Rasch model," International Journal of Engineering and Technology (UAE), 7(4), 2018, pp. 32-36. 